\title{
Evaluation of Glomerular Hyperfiltration and Albuminuria in Sickle Cell Disease Adolescents: Cross-Sectional Retrospective Study
}

\author{
Nosakhare Joyce Iduoriyekemwen ${ }^{1,2}$, Caroline Booth ${ }^{3}$, Marilyn McDougall4, \\ Psalm Duniya Baba Inusa ${ }^{5}$ \\ ${ }^{1}$ Advance Paediatric Masters Programme, King's College London, London, UK \\ ${ }^{2}$ Paediatric Nephrology Unit, Department of Child Health, University of Benin Teaching Hospital, Benin City, Nigeria \\ ${ }^{3}$ Department of Paediatric Nephrology, Evelina Children Hospital, London, UK \\ ${ }^{4}$ Department of Paediatric Critical Care, Evelina Children Hospital, London, UK \\ ${ }^{5}$ Department of Paediatric Haematology, Evelina Children Hospital, London, UK \\ Email: *nosaiduos2006@yahoo.com
}

How to cite this paper: Iduoriyekemwen, N.J., Booth, C., McDougall, M. and Inusa, P.D.B. (2021) Evaluation of Glomerular Hyperfiltration and Albuminuria in Sickle Cell Disease Adolescents: Cross-Sectional Retrospective Study. Open Journal of Nephrology, 11, 321-334.

https://doi.org/10.4236/ojneph.2021.113026

Received: May 15, 2021

Accepted: July 13, 2021

Published: July 16, 2021

Copyright $\odot 2021$ by author(s) and Scientific Research Publishing Inc. This work is licensed under the Creative Commons Attribution International License (CC BY 4.0).

http://creativecommons.org/licenses/by/4.0/

\begin{abstract}
Background: Sickle Cell Disease (SCD) renal abnormalities commence early in childhood. The glomerular abnormalities, glomerular hyperfiltration and albuminuria are the most prevalent. However, these SCD glomerulopathies have not been considered exclusively in the adolescent age group. Objective: To determine the prevalence of glomerular hyperfiltration and albuminuria as well as identify the determinants for glomerular hyperfiltration in adolescents with SCD. Patients and Methods: The electronic patient records of 153 adolescents with SCD aged $10-<19$ years, attending the Paediatrics Haematology Clinic at Evelina London Children's Hospital, United Kingdom, were reviewed from the $10^{\text {th }}$ to $23^{\text {rd }}$ June 2019. Clinical information and laboratory parameters were obtained. The glomerular filtration rate was derived using the Bedside Schwartz's method. Grouping of the adolescents was based on the presence and absence of glomerular hyperfiltration, which was defined as glomerular filtration rate $>140 \mathrm{ml} / \mathrm{min} / \mathrm{m}^{2}$. The presence of albuminuria was defined as urine albumin-to-creatinine ratio $>3 \mathrm{mg} / \mathrm{mmol}$ or protein-to-creatinine ratio of $>15 \mathrm{mg} / \mathrm{mmol}$. The clinical and laboratory determinants of glomerular hyperfiltration in the total study population were investigated. Result: Prevalence of glomerular hyperfiltration was $33.3 \%$ in the adolescents studied, and that of albuminuria was $15.7 \%$ amongst the SCD adolescents studied, of which $13.7 \%$ of those with glomerular hyperfiltration also had albuminuria. On univariable analysis, the SCD adolescents with glomerular hyperfiltration had significantly lower weight $(48.0 \pm 18.0$ versus $54.8 \pm 17.0$ $\mathrm{kg} ; p=0.02)$, height $(155.1 \pm 13.1$ versus $160.6 \pm 13.1 \mathrm{~cm} ; p=0.01)$, body
\end{abstract}


mass index $(19.4 \pm 5.0$ versus $21.0 \pm 4.3 ; p=0.04)$, haemoglobin level $(88.7 \pm$ 13.3 versus $98.1 \pm 21.7 \mathrm{~g} / \mathrm{L} ; p=0.001)$, and serum creatinine level $(0.4 \pm 0.1$ versus $0.6 \pm 0.2 \mathrm{mg} / \mathrm{dl} ; p=0.0001)$ as compared to those with no glomerular hyperfiltration. The SCD adolescents with glomerular hyperfiltration also had significantly higher lactate dehydrogenase levels (525.9 \pm 180.3 versus $449.6 \pm$ $170.3 \mathrm{IU} / \mathrm{L} ; p=0.01$ ) than those with no glomerular hyperfiltration. But, multivariable analysis revealed no associations. Conclusion: This study revealed that the prevalence of glomerular hyperfiltration in SCD children in the adolescent age group is high, and the high glomerular filtration rates begin to decline toward normal values in middle adolescence.

\section{Keywords}

Glomerular Hyperfiltration, Albuminuria, Sickle Cell Disease, Adolescent

\section{Introduction}

Sickle Cell Disease (SCD) is the most common inherited red blood cell disorder [1]. The global incidence is estimated at 300,000 new-borns annually [2]. This figure is predicted to rise by $30 \%$ due to improved life expectancy, with more children surviving into adulthood by 2050 [3]. Identified reasons for improvements in survival are the availability of comprehensive care programmes, including neonatal screening, which facilitates early access to penicillin prophylaxis, pneumococcal and influenza vaccination, growth and development monitoring, dietary advice and parental education, which enhances prompt consultation [1]. Although advances in children's care with SCD have improved, these children's long-term survival implies that chronic morbidities from the disease such as chronic heart disease, pulmonary hypertension, chronic leg ulcers, and chronic kidney disease will be more prevalent.

The renal complications of SCD are a spectrum of renal abnormalities collectively referred to as Sickle Cell Nephropathy (SCN) [4]. SCN manifests early in childhood as glomerular hyperfiltration, microalbuminuria and hyposthenuria. In late childhood, the microalbuminuria progressively increases with the development of albuminuria which may be associated with regression of the glomerular filtration rate, which can subsequently develop in Chronic Kidney Disease (CKD) in late adolescence and, in the extreme case, End-Stage Renal Disease (ESRD) develops in early adulthood [5].

Glomerular hyperfiltration and its accompanying glomerular hypertrophy are the earliest glomerular abnormalities in SCD [6]. It manifests clinically as markedly elevated GFR. Its aetiology in SCD is not clearly understood but, its development and progression are believed to be driven by increased glomerular perfusion and increased effective glomerular filtration surface area, but not by increased glomerular capillary hydrostatic pressure [7]. The reported prevalence of glomerular hyperfiltration in SCD, mainly in children with SCA, ranges from 
$40 \%$ to $98 \%$ [8] [9] [10]. These prevalence rates differ from study to study because there is no uniform definition of glomerular hyperfiltration. Brewin et al. noted that the threshold used from most paediatric studies was between 130 $140 \mathrm{ml} / \mathrm{min} / \mathrm{m}^{2}$ [9]. Utilizing a single criterion for all ages of children may be inaccurate; this may be responsible for the high prevalence rate of glomerular hyperfiltration in the literature. Hence in this study, the standard clinical definition of glomerular hyperfiltration, which is $>140 \mathrm{ml} / \mathrm{min} / \mathrm{m}^{2}$ [9] was restricted to only the adolescent age group. Besides, there are no studies on the prevalence of glomerular hyperfiltration exclusively in the adolescent age group of children with SCD, implying that the proportion of children with SCD that may develop $\mathrm{CKD}$ in later life is unknown.

Glomerular Hyperfiltration in children with SCD has been documented to be present throughout childhood [8] [9] [11]. However, conflicting reports exist on the rates in adolescents. Wigfall et al. and Aygun et al. reported that GFR declines towards normal range in the second decade of life [8] [11], while Brewin et al. observed that the elevated GFR did not vary with age [9]. These contradicting reports may have arisen because a small number of adolescents were represented in the adolescent group of these studies. These varying reports further buttress the need for glomerular hyperfiltration to be studied exclusively in the adolescents' population.

Proteinuria is the most frequent clinical evidence of SCD glomerulopathy [12]. Children with SCD present with proteinuria of varying degrees which are: microalbuminuria, macroalbuminuria, and rarely nephrotic range proteinuria. The development of albuminuria in SCD is believed to be due to several factors: glomerular hyperfiltration, glomerular hypertension, ischemia-reperfusion injury, oxidative stress, and decreased Nitric Oxide (NO) bioavailability, and endothelial dysfunction [12]. The prevalence of microalbuminuria in children with SCA ranges from 16\% - 27\% from several studies [8] [13] [14] [15] [16] [17]. From several research works, the prevalence of macroalbuminuria in children with SCA is $6 \%-23 \%$ [6] [11]. It has been reported to increase with increasing age in children [11] as well as in adults [18]. Although some authors [13] reported that the prevalence of albuminuria is higher when considering purely adolescent populations, their criteria for albuminuria is not the standard definition; therefore, the prevalence of albuminuria amongst the adolescent SCD population is also not known. Thus, the purpose of this study was to determine the prevalence of glomerular hyperfiltration and albuminuria, as well as the determinants of glomerular hyperfiltration in adolescents with SCD.

\section{Methods}

\subsection{Patients}

In this cross-sectional study, a review of the electronic patient records of the children attending the Paediatrics Haematology Clinic at Evelina London Children's Hospital, United Kingdom, was carried out between $10^{\text {th }}$ to $23^{\text {rd }}$ June 2019. 
The adolescents recruited from the database were $10-<19$ years with the diagnosis of SCD. The adolescents excluded were those with associated comorbidities that may affect their renal function, such as chronic lung disease, chronic heart disease, endocrine dysfunction, diabetes mellitus, human immunodeficiency virus (HIV), Hepatitis B virus or Hepatitis C virus infection, including those with pre-existing kidney disease. This was to ensure that SCD alone clearly explains the development of glomerular abnormalities.

\subsection{Data Collection}

Clinical data obtained from the most recent outpatient visit included age, gender, sickle cell type. The clinical history details included were: acute events -Vaso-Occlusive Crisis (VOC), Acute Chest Syndrome (ACS), Cerebrovascular Accident (CVA), acute sequestration crisis; the history of chronic blood transfusion; duration on chronic blood transfusion; the age of onset of chronic blood transfusion; the history of hydroxyurea use; duration on hydroxyurea use. The physical examination parameters obtained were: weight, height, body mass index, systolic blood pressure and diastolic blood pressure. The laboratory parameters obtained were urine albumin-creatinine ratio or protein-creatinine ratio, haemoglobin level, white blood cell count, red blood cell count, platelet count, reticulocyte count, foetal haemoglobin level, lactate dehydrogenase level, serum creatinine and serum ferritin level. The Bedside Schwartz method [19] was used to determine the GFR, recommended by the Kidney Disease: Improving Global Outcomes [20] to evaluate renal function in children. The formula is the constant $0.413 \times$ height in $\mathrm{cm} /$ serum creatinine in $\mathrm{mg} / \mathrm{dl}$.

\subsection{Definition of Terms}

Glomerular hyperfiltration was defined as GFR $>140 \mathrm{ml} / \mathrm{min} / \mathrm{m}^{2}$. While albuminuria was defined as urine Albumin Creatinine Ratio (ACR) $>3 \mathrm{mg} / \mathrm{mmol}$ or urine Protein Creatinine Ratio (PCR) of $>15 \mathrm{mg} / \mathrm{mmol}$, depending on which was available for the patient. Albuminuria was further classified into microalbuminuria defined as urine ACR $3-30 \mathrm{mg} / \mathrm{mmol}$ or urine PCR of $15-50 \mathrm{mg} / \mathrm{mmol}$ and macroalbuminuria as urine ACR $>30 \mathrm{mg} / \mathrm{mmol}$ or urine PCR $>50$ $\mathrm{mg} / \mathrm{mmol}$ [20]. The adolescents were categorised into two groups, hyperfiltration present and hyperfiltration absent. The adolescence was categorised into three age groups early adolescence 10 - 13 years, mid-adolescence $14-16$ years, and late adolescence $17-<19$ years [21].

\subsection{Ethical Approval}

Ethical approval, with project number 9949, issued by the Clinical Governance Committee for Service Improvement, Evelina London Children's Hospital, Guy's and St Thomas NHS Foundation Trust, dated 19-August 2019.

\subsection{Data Analysis}

The data collected were analysed using International Business Machines, Statis- 
tical Package for the Scientific Solutions (SPSS) version 24 (SPSS for Window Inc.; Chicago, IL, USA) Statistical software. Continuous variables; age, the physical clinical parameters such as weight, height and laboratory parameters and the GFR were summarised as mean \pm Standard Deviation (SD), while categorised variables; age group, clinical histories, and presence of albuminuria represented as proportions. Pearson's chi-square or Fishers Exact tests were used in comparing the categorised variable of the two groups (age group, gender, history of acute event, history of blood transfusion, and hydroxyurea therapy). The continuous parametric data (age, weight, height, BMI, systolic blood pressure, diastolic blood pressure, haemoglobin level, red blood cell count, white blood cell count, reticulocyte count, platelet count, lactate dehydrogenase level and serum creatinine level) of the two groups of children were compared by Student $\mathrm{t}$-test. While the Mann Whitney $U$ test was used in analysing the non-parametric variable (foetal haemoglobin level and serum ferritin level). Multivariable logistic regression analysis was used to identify the factors associated with glomerular hyperfiltration. The level of significance of each test was set at a $P$-value of $<$ 0.05 .

\section{Results}

Following the review of the electronic database of the Paediatric Haematology Clinic, 217 patients with SCD aged $10-<19$ years were identified. Of these, 153 were recruited, and 64 were excluded. Nine of the adolescents were excluded because they had chronic comorbidities (four chronic heart disease, three chronic lung diseases, and two chronic kidney diseases). Also excluded were four of the adolescents who had undergone stem cell transplantation and were on immunotherapy, while the remaining 51 excluded were because of incomplete results. The flow chat shows the details of the recruitment process (Figure 1).

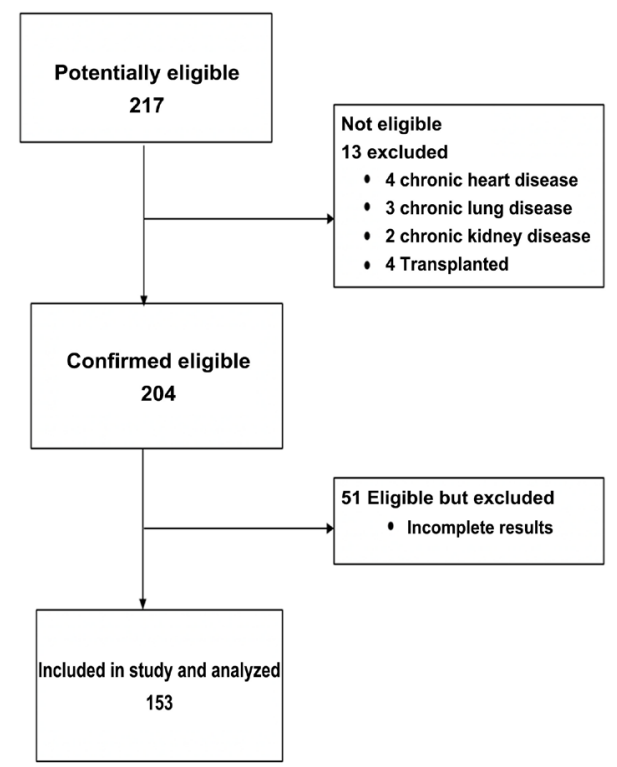

Figure 1. Flow diagram showing the exclusion process. 


\subsection{Demographic and Clinical Details of the Adolescents Studied}

The mean (SD) ages of the adolescents were $13.73 \pm 2.5$ years. Most were in the 10 - 13 years old age group, $70(45.8 \%)$ and were females 79 (51.6\%). Most of the adolescents had Hb SS disease 115 (75.2\%), 31 (20.3\%) had Hb SC, and 5 (3.3\%) had $\mathrm{Hb} \mathrm{S} / \mathrm{beta}^{+}$thalassemia. Demographic characteristics and distribution of the types of SCD of all the adolescents studied are shown in Table 1. Of the 153 adolescents studied, $94(61.4 \%)$ had a history of an acute event (Forty-nine (52.1\%) of these adolescents had experienced severe, frequent vaso-occlusive crisis (VOC), 28 (29.8\%) had a history of ACS, 12 (12.7\%) CVA, 3 (3.2\%) acute sequestration crisis and $2(2.1 \%)$ had a history of both ACS and CVA. Ninety-two $(60.1 \%)$ of the adolescents studied were on sickle cell modifying therapy. Seventy (76.1\%) were on hydroxyurea therapy, and $22(23.9 \%)$ were on chronic blood transfusion, while the remaining 61 (39.9\%) adolescents were not on any sickle cell modifying therapy. The most frequent reasons for treatment among the 92 adolescents on sickle cell modifying therapy were severe frequent VOC 57 (62\%), abnormal transcranial scan indicative of impending CVA $19(20.6 \%)$ and CVA 10 (10.8\%). Figure 2 shows the reasons for sickle cell modifying therapy. The glomerular filtration rate of the studies population shows a decrease with increasing age, see Figure 3. The median (interquartile range) GFR for those in the age 10 - 13 years was $132.5(114.7-151.3) \mathrm{ml} / \mathrm{min} / \mathrm{min}^{2}$, it was $122.0(105.0-$ $143.5) \mathrm{ml} / \mathrm{min} / \mathrm{min}^{2}$; for those in the $14-16$ years age group and 107 (83.6 - 130) $\mathrm{ml} / \mathrm{min} / \mathrm{min}^{2}$; for those in the $17-<19$ years.

\subsection{Glomerular Hyperfiltration}

Of the 153 adolescents with SCD, 51 (33.3\%) had glomerular hyperfiltration but absent in 102 (66.7\%). The mean estimated glomerular filtration rate of the SCD

Table 1. Demographic characteristics of the study population.

\begin{tabular}{lc}
\hline Characteristics & $\mathbf{n}(\%) \mathbf{n}=153$ \\
\hline Age. Mean \pm SD in years & $13.7 \pm 2.5$ \\
Age Group & $70(45.8)$ \\
$10-13$ years & $57(37.3)$ \\
$14-16$ years & $26(17.0)$ \\
$17-<19$ years & \\
Gender & $79(51.6)$ \\
Female & $74(48.4)$ \\
Male & \\
Haemoglobin S distribution & $115(75.2)$ \\
Hb SS & $31(20.3)$ \\
Hb SC & $5(3.3)$ \\
Hb S/Sickle B thal & $2(1.3)$ \\
Other & \\
\hline
\end{tabular}




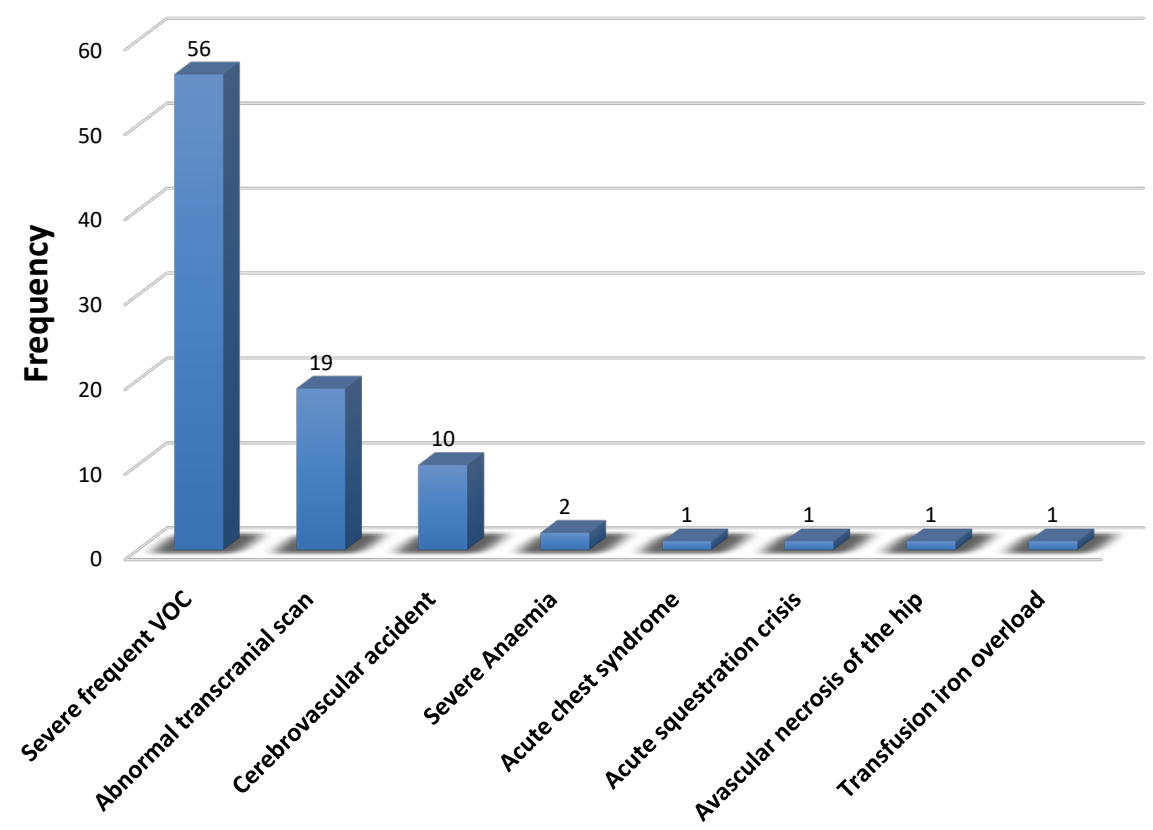

Figure 2. Reasons for being on sickle cell modifying therapy.

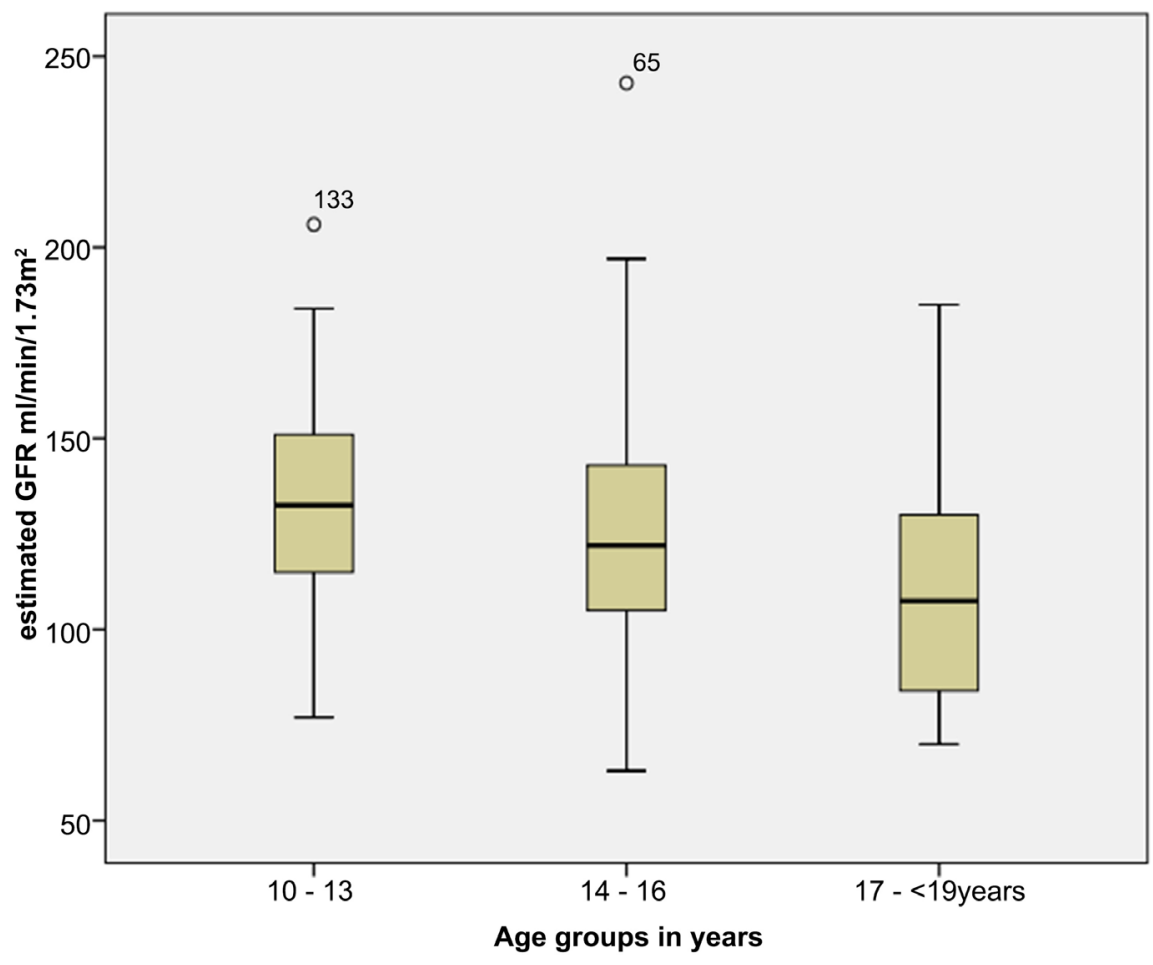

Figure 3. Box plot of the estimated glomerular filtration rate categorised into age groups.

adolescents who had hyperfiltration was $160.2 \pm 20.0 \mathrm{ml} / \mathrm{min} / 1.73 \mathrm{~m}^{2}$, and that of those with no hyperfiltration was $109.9 \pm 19.3 \mathrm{ml} / \mathrm{min} / \mathrm{min}^{2}$.

The SCD adolescents with hyperfiltration were significantly younger than those without it. The mean age of those with hyperfiltration was $13.0 \pm 2.4$ years, while it was $14.1 \pm 2.6$ years for those with no hyperfiltration $P=0.01 \mathrm{CI}:-1.904$ 
- -0.213 . There was no statistically significant difference in gender; however, they were more females amongst the SCD adolescents with hyperfiltration 28 (54.9\%) versus 23 (45.1\%), while the proportion of the males and females in the group of adolescents with no hyperfiltration were similar (See Table 2). A significantly higher percentage of adolescents with SCD who had hyperfiltration had the HbSS disease (47 (92.2\%) versus 68 (66.7\%); $P=0.007)$. However, among those with the HbSC disease variant, those with no hyperfiltration were more than those with hyperfiltration (27 (26.5\%) versus 4 (7.8\%)). Also, a higher proportion of SCD adolescents with hyperfiltration were on hydroxyurea therapy than those with no hyperfiltration $31(60.8 \%)$ versus 39 (38.2\%); $p=0.01$. However, there was no significant difference between adolescents with hyperfiltration and those without hyperfiltration regarding the type of acute events they had experienced or their blood transfusion history. The demographic and clinical history of those with hyperfiltration and those with no hyperfiltration depicted in Table 2.

Table 3 shows the physical examination measurements and laboratory variables of the SCD adolescent with hyperfiltration and those with no hyperfiltration.

Table 2. Demographic and clinical history of those with hyperfiltration and those with no hyperfiltration

\begin{tabular}{|c|c|c|c|}
\hline \multirow{3}{*}{ Characteristics } & \multicolumn{3}{|c|}{ Hyperfiltration present Hyperfiltration absent } \\
\hline & $\mathrm{n}(\%)$ & n (\%) & $P$-value \\
\hline & $\mathrm{n}=51(33.3)$ & $\mathrm{n}=102(66.7)$ & \\
\hline \multicolumn{4}{|l|}{ Age group } \\
\hline $10-13$ years & $29(56.9)$ & $41(40.2)$ & \multirow{3}{*}{0.05} \\
\hline $14-16$ years & $18(35.3)$ & $39(38.2)$ & \\
\hline $17-<19$ years & $4(7.8)$ & $22(21.6)$ & \\
\hline \multicolumn{4}{|l|}{ Gender } \\
\hline Female & $28(54.9)$ & $51(50)$ & \multirow{2}{*}{0.609} \\
\hline Male & $23(45.1)$ & $51(50)$ & \\
\hline \multicolumn{4}{|l|}{ Haemoglobin Variants } \\
\hline $\mathrm{Hb}$ SS & $47(92.2)$ & $68(66.7)$ & \multirow{4}{*}{0.007} \\
\hline HB SC & $4(7.8)$ & $27(26.5)$ & \\
\hline Sickle $\mathrm{B}^{+}$thal & $0(0.0)$ & $5(4.9)$ & \\
\hline Other & $0(0.0)$ & $2(2.0)$ & \\
\hline \multicolumn{4}{|l|}{ History of Acute events } \\
\hline Severe recurrent VOC & $21(41.2)$ & $28(27.5)$ & \multirow{6}{*}{0.405} \\
\hline Acute chest syndrome & $9(17.6)$ & $19(18.6)$ & \\
\hline Cerebrovascular accident & $5(9.8)$ & $7(6.9)$ & \\
\hline Acute sequestration crisis & $1(2.0)$ & $2(2.0)$ & \\
\hline Combination of ACS/CVA & $1(2.0)$ & $1(1.0)$ & \\
\hline None & $14(27.5)$ & $45(44.1)$ & \\
\hline \multicolumn{4}{|l|}{ History of Chronic Blood Transfusion } \\
\hline Yes & $5(9.8)$ & $17(16.7)$ & \multirow{2}{*}{0.331} \\
\hline No & $46(90.2)$ & $85(83.3)$ & \\
\hline \multicolumn{4}{|l|}{ History of Hydroxyurea therapy } \\
\hline Yes & $31(60.8)$ & $39(38.2)$ & \multirow{2}{*}{0.01} \\
\hline No & $20(39.2)$ & $63(61.8)$ & \\
\hline
\end{tabular}


Table 3. Physical examination measurements and laboratory variables of the SCD adolescent with hyperfiltration and those with no hyperfiltration.

\begin{tabular}{|c|c|c|c|c|}
\hline Variables & $\begin{array}{c}\text { Hyperfiltration } \\
\text { Present } \\
n=51 \\
\text { mean } \pm S D\end{array}$ & $\begin{array}{c}\text { Hyperfiltration } \\
\text { Absent } \\
\mathrm{n}=102 \\
\text { mean } \pm \mathrm{SD}\end{array}$ & $P$-value & $\begin{array}{c}\text { Confidence } \\
\text { interval }\end{array}$ \\
\hline Weight in $\mathrm{Kg}^{*}$ & $48.0 \pm 18.0$ & $54.8 \pm 17.0$ & 0.026 & $-12.807--0.843$ \\
\hline Height in $\mathrm{cm}^{*}$ & $155.1 \pm 13.1$ & $160.6 \pm 13.1$ & 0.016 & $-10.003--1.026$ \\
\hline $\mathrm{BMI}^{*}$ & $19.4 \pm 5.0$ & $21.0 \pm 4.3$ & 0.043 & $-3.172--0.048$ \\
\hline $\mathrm{SDP}$ in $\mathrm{mmHg}$ & $110.0 \pm 10.8$ & $112.9 \pm 10.2$ & 0.107 & $-6.435-0.631$ \\
\hline $\mathrm{DBP}$ in $\mathrm{mmHg}$ & $63.6 \pm 8.9$ & $65.5 \pm 8.6$ & 0.201 & $-4.856-1.033$ \\
\hline Haemoglobin levels $\mathrm{g} / \mathrm{L}$ & $88.7 \pm 13.3$ & $98.1 \pm 21.7$ & 0.001 & $-14.988-3.744$ \\
\hline Red blood cell count $\times 10^{12} / \mathrm{L}$ & $3.4 \pm 2.7$ & $3.6 \pm 0.9$ & 0.686 & $-0.946-0.627$ \\
\hline White blood cell count $\times 10^{9} / \mathrm{L}$ & $9.7 \pm 4.1$ & $8.7 \pm 3.6$ & 0.160 & $-0.384-2.294$ \\
\hline Reticulocyte count $\times 10^{9} / \mathrm{L}$ & $222.5 \pm 104.3$ & $190.9 \pm 93.6$ & 0.071 & $-2.784-65.941$ \\
\hline Platelet count $\times 10^{9} / \mathrm{L}$ & $326.5 \pm 141.6$ & $280.2 \pm 124.2$ & 0.050 & $-0.019-92.688$ \\
\hline Haemoglobin F levels \% & $8.1 \pm 6.3$ & $8.3 \pm 9.0$ & $0.376^{+}$ & \\
\hline Lactate dehydrogenase level IU/L & $525.9 \pm 180.3$ & $449.6 \pm 170.3$ & 0.014 & $16.111-136.653$ \\
\hline Serum ferritin levels $\mu \mathrm{g} / \mathrm{L}$ & $852.0 \pm 1606.1$ & $744.2 \pm 1541.6$ & $0.211^{+}$ & \\
\hline Serum creatinine levels $\mathrm{mg} / \mathrm{dl}$ & $0.4 \pm 0.1$ & $0.6 \pm 0.2$ & 0.0001 & $-0.261--0.193$ \\
\hline
\end{tabular}

${ }^{*}$ Missing data weight 5 Height 4 BMI 5 BMI Body mass index; SBP: Systolic blood pressure; DBP: Diastolic blood pressure; ${ }^{+}$Statistic test was Mann-Whitney U.

The adolescents with hyperfiltration had significantly lower weight $(48.0 \pm 18.0$ versus $54.8 \pm 17.0 \mathrm{~kg} ; p=0.02)$, height $(155.1 \pm 13.1$ versus $160.6 \pm 13.1 \mathrm{~cm} ; p=$ $0.01)$, BMI (19.4 \pm 5.0 versus $21.0 \pm 4.3 ; p=0.04)$ haemoglobin level $(88.7 \pm 13.3$ versus $98.1 \pm 21.7 \mathrm{~g} / \mathrm{L} ; p=0.001)$, and serum creatinine level $(0.4 \pm 0.1$ versus 0.6 $\pm 0.2 \mathrm{mg} / \mathrm{dl} ; p=0.0001)$ as compared to those with no hyperfiltration. The adolescents with hyperfiltration also had significantly higher lactate dehydrogenase levels $(525.9 \pm 180.3$ versus $449.6 \pm 170.3 \mathrm{IU} / \mathrm{L} ; p=0.01)$ compared to those with no hyperfiltration. Other parameters, namely their systolic blood pressures, diastolic blood pressure, red blood cell count, white blood cell count, reticulocyte count, platelet count, haemoglobin F levels, and serum ferritin levels, not significantly different in the two groups of adolescents with SCD. No factor was associated with glomerular hyperfiltration on multivariable analysis; Table 4 shows the factors analysed using multivariable logistics regression.

\subsection{Albuminuria}

Twenty-four (15.7\%) of the total normal of the adolescents with SCD studies had albuminuria, of which 22 (91.7\%) had microalbuminuria, and 2 (8.3) had macroalbuminuria, thus in this study, the prevalence of microalbuminuria was $14.4 \%$, and $1.3 \%$ was the prevalence of overt proteinuria. In this study, the proportion of albuminuria did not vary with increasing age. The age group-specific 
Table 4. Logistic regression models showing the factors associated with glomerular hyperfiltration.

\begin{tabular}{ccccc}
\hline Factors & $\beta$ Coefficient & Odds ratio & $\begin{array}{c}\text { 95\% Confidence } \\
\text { interval }\end{array}$ & $p$-value \\
\hline Age in years & -0.129 & 0.879 & $0.760-1.016$ & 0.082 \\
Hemoglobin level g/L & -0.017 & 0.983 & $0.964-1.004$ & 0.108 \\
Lactate dehydrogenase level IU/L & 0.001 & 1.001 & $0.999-1.004$ & 0.194 \\
\hline
\end{tabular}

prevalence was $6.5 \%$ for both the age groups $10-13$ years and $14-16$ years respectively, while $2.6 \%$ for the age group $17-<19$ years. Most of the children with albuminuria had Haemoglobin SS disease 18 (75.0\%), 4 (16.7\%) had haemoglobin SC, while $1(4.2 \%)$ each had the Sickle cell $\beta^{+}$thalassemia and HBS/HPFH variant, respectively.

\section{Discussion}

Glomerular hyperfiltration and albuminuria are the earliest evidence of renal impairment in SCD. This study is one of the first studies evaluating renal glomerular abnormalities exclusively in the adolescent SCD population. In this observational study, the prevalence of glomerular hyperfiltration and albuminuria were determined. The adolescents with SCD who had glomerular hyperfiltration were compared to those with no hyperfiltration.

From this study, a high proportion of adolescents with SCD had glomerular hyperfiltration, but the unavailability of similar studies in the adolescent age group of children with SCD precludes comparison. Nevertheless, since glomerular hyperfiltration is believed to be one of the drivers of renal glomerulopathy in SCD, this high prevalence of glomerular hyperfiltration observed in this study provides further evidence that a large proportion of children with SCD enter adult life already experiencing early asymptomatic glomerular abnormalities, which may subsequently develop into CKD. This highlights the importance of regular determination of glomerular filtration rate in children to ensure early identification and follow-up of the children that may develop chronic kidney disease in the future.

This study's finding that none of the factors examined was associated with glomerular hyperfiltration is at variance with previous studies. In the paediatric age group, the only available research on the determinants of glomerular hyperfiltration [10], reported that older age and reduced body mass index were factors associated with glomerular hyperfiltration. However, this study cannot be compared to the previous study because their definition of glomerular hyperfiltration differs. While this study defined glomerular hyperfiltration as GFR $>140 \mathrm{~min} /$ $\mathrm{ml} / 1.73 \mathrm{~m}^{2}$ according to the standard clinical definition, the previous study's definition was GFR less than $140 \mathrm{~min} / \mathrm{ml} / 1.73 \mathrm{~m}^{2}$. Furthermore, this study's finding of no factor associated with glomerular hyperfiltration is also at variance with studies in the adult population. Haymann et al. reported that hyperfiltration was 
associated with young age, a lower haemoglobin level and lower fetal haemoglobin level, of note this adult study included adolescents as young as 16 years [22].

Other studies by Aygun et al. and Wigfall et al. [8] [11] report that GFR decline toward normal during the adolescent years in children with SCD. In this study examining the adolescent age group alone, a progressive decline in GFR is observed. However, the onset age for the decline in GFR in this study is earlier than that reported by Aygun et al. In this current study GFR declined from the age group 14 years, but it was stated to decline from 16 years in the previous study [8]. Glomerular filtration rate differs depending on the method used in its determination. In this study, it was the creatinine-based Bedside Schwarz formula which is known to overestimate glomerular filtration rate, while in the study by Aygun et al., measured glomerular filtration rate by plasma clearance of 99-technetium diethylenetriamine pentaacetate (99Tc-DTPA) was used, which correlated well with the gold standard inulin clearance [8]. This difference in methods used in the two studies may be responsible for the age difference regarding when the glomerular filtration rate decline in adolescents with SCD.

In this study, the adolescents with HbSS were more in the glomerular hyperfiltration group. Those with HbSC disease were predominantly in the group with no glomerular hyperfiltration, and those with all other types of sickle cell haemoglobin variant were also in the group with no glomerular hyperfiltration. This finding suggests that glomerular involvement in SCD is dependent on disease severity. Haemoglobin SC disease and sickle cell $\beta^{+}$thalassemia are known to run a milder course with less frequent vaso-occlusive crises and other acute complications than SCA disease. In the study by Platt et al. on pain in sickle cell disease, they reported that the average rate of pain episode per patient-years in their SCA patient was 0.8 , and this rate was twice that observed in their haemoglobin SC disease patient and those with sickle cell $\beta^{+}$thalassemia [23]. Also. Castro et al. demonstrated that the incidence of acute chest syndrome was more amongst patients with sickle cell anaemia than those with Haemoglobin SC disease [24]. These studies support the notion that less vaso-occlusion results in reduced frequency of acute events, resulting in less chronic organ involvement; hence the kidney may be protected from glomerulopathy in milder SCD variants.

The prevalence of albuminuria in this study is inconsonant with the studies by Becton et al., Aygun et al., Brewin et al., who reported a proteinuria prevalence of $15.1 \%, 15.5 \%$ and $15.9 \%$, respectively [8] [9] [17]. Of note, in these studies, albuminuria was predominately observed after the age of 10years supporting the observation by other authors that glomerular damage possibly commences from the second decade of life. In this study, albuminuria was predominately microalbuminuria, and its prevalence amongst the adolescents with SCD was similar to a previous report by Alvarez et al., who reported a microalbuminuria prevalence of $19 \%$ in their children ten years and older [16]. It was, however, in contrast with the report of Dharnidharka et al. that observed a microalbuminuria prevalence of $46 \%$ amongst their adolescent studied [13]. In the study by Dhar- 
nidharka et al. the definition of microalbuminuria was urine albumin/creatinine ratio $>20 \mathrm{mg} / \mathrm{g}$, which is $1.77 \mathrm{mg} / \mu \mathrm{mol}$. This may have been responsible for the higher prevalence observed in that study.

The strength of this study is that it is the first study examining the characteristics and association of glomerular hyperfiltration in an exclusively adolescent population with a large sample size. One of the limitations of this study is its retrospective design. Since the data were obtained from a secondary source not intentionally recorded for research, missing data were observed for some variables; however, these were few. Another possible limitation that the study design may confer is the issue of measurement error. In particular, a potential limitation of this study is the serum creatinine-based formula used in deriving the estimated GFR. The Bedside Schwartz formula [19] can overestimate GFR because creatinine is secreted in the proximal tubules in healthy individuals. This physiological process may hyperfunction in individuals with SCD, resulting in increased creatinine secretion [25]. Aygun et al. compared measured GFR by plasma clearance with 99Tc-DTPA, which has been shown to correlate with the inulin clearance, the gold standard with and creatinine-based formulas [8]. They reported that the estimates of GFR by the modified Schwartz formula [26] positively correlated with the measured glomerular filtration rate by the plasma 99Tc-DTPA clearance [8]. This modified Schwartz formula was not used in this study as it requires estimates of serum cystatin C to compute the GFR estimates, which were unavailable as it was not routinely measured. Despite these limitations, the Bedside Schwartz formula [19] used in this study is currently the best non-invasive clinically approach in estimating GFR in children and adolescents. Finally, in this study on SCD, the comparison was mainly made to other studies on SCA alone. These studies are the available literature on glomerular hyperfiltration and albuminuria in children; nevertheless, most of the adolescents investigated in this current study had SCA.

In conclusion, this is the first adolescent SCD study demonstrating the prevalence of glomerular hyperfiltration, its associated factors and its relationship with albuminuria in a single cohort. This finding would be strengthened by prospectively monitoring renal function in a multicenter study.

\section{Conflicts of Interest}

The authors declare no conflicts of interest regarding the publication of this paper.

\section{References}

[1] Rees, D.C., William, T.N. and Gladwin, M.T. (2010) Sickle-Cell Disease. The Lancet, 376, 2018-2031. https://doi.org/10.1016/S0140-6736(10)61029-X

[2] Modell, B. and Darlison, M. (2008) Global Epidemiology of Haemoglobin Disorders and Derived Service Indicators. Bulletin of the World Health Organization, 86, 480-487. https://doi.org/10.2471/BLT.06.036673

[3] Piel, F.B., Hay, S.I., Gupta, S., Weatherall, D.J. and William, T.N. (2013) Global 
Burden of Sickle Cell Anaemia in Children under Five, 2010-2050: Modelling Based on Demographics, Excess Mortality, and Interventions. PLoS Medicine, 10, e1001484. https://doi.org/10.1371/journal.pmed.1001484

[4] Nath, K.A. and Hebbel, R.P. (2015) Sickle Cell Disease: Renal Manifestations and Mechanisms. Nature Reviews Nephrology, 11, 161-171.

https://doi.org/10.1038/nrneph.2015.8

[5] Inusa, B.P., Mariachiara, L., Giovanni, P. and Ataga, K.I., (2018) Sickle Cell Nephropathy: Current Understanding of the Presentation, Diagnostic and Therapeutic Challenges. In: Hematology-Latest Research and Clinical Advances, 1st Editon, IntechOpen, London, 156-185. https://doi.org/10.5772/intechopen.76588

[6] Yee, M.M., Jabbar, S.F., Osunkwo, I., Clement, L., Lane, P.A., Eckman, R.J., et al. (2011) Chronic Kidney Disease and Albuminuria in Children with Sickle Cell Disease. Clinical Journal of the American Society of Nephrology, 6, 2628-2633. https://doi.org/10.2215/CJN.01600211

[7] Helal, I., Fick-Brosnahan, G.M., Reed-Gitomer, B. and Schrier, R.W. (2012) Glomerular Hyperfiltration: Definitions, Mechanisms and Clinical Implications. Nature Reviews Nephrology, 8, 293-300. https://doi.org/10.1038/nrneph.2012.19

[8] Aygun, B., Mortier, N.A., Smeltzer, M.P., Hankins, J.S. and Ware, R.E. (2011) Glomerular Hyperfiltration and Albuminuria in Children with Sickle Cell Anemia. Pediatric Nephrology, 26, 1285-1290. https://doi.org/10.1007/s00467-011-1857-2

[9] Brewin, J., Tewari, S., Hannemann, A., Al Balushi, H., Sharpe, C., Gibson, J.S. and Rees, D.C. (2017) Early Markers of Sickle Nephropathy in Children with Sickle Cell Anemia Are Associated with Red Cell Cation Transport Activity. HemaSphere, 1, e2. https://doi.org/10.1097/HS9.0000000000000002

[10] Aloni, M.N., Ngiyulu, R.M., Ekulu, P.M., Mbutiwi, F.I., Makulo, J.R., Gini-Ehungu, J.L., et al. (2017) Glomerular Hyperfiltration Is Strongly Correlated with Age in Congolese Children with Sickle Cell Anaemia. Acta Paediatrica, 106, 819-824. https://doi.org/10.1111/apa.13784

[11] Wigfall, D.R., Ware, R.E., Burchinal, M.R., Kinney, T.R. and Foreman, J.W. (2000) Prevalence and Clinical Correlates of Glomerulopathy in Children with Sickle Cell Disease. Journal of Pediatrics, 136, 749-753.

https://doi.org/10.1067/mpd.2000.105998

[12] Ataga, K.I., Derebail, V.K. and Archer, D.R. (2014) The Glomerulopathy of Sickle Cell Disease. American Journal of Hematology, 89, 907-914. https://doi.org/10.1002/ajh.23762

[13] Dharnidharka, V.R., Dabbagh, S., Atiyeh, B., Simpson, P. and Sarnaik, S. (1998) Prevalence of Microalbuminuria in Children with Sickle Cell Disease. Pediatric Nephrology, 12, 475-478. https://doi.org/10.1007/s004670050491

[14] King, L., MooSang, M., Miller, M. and Reid, M. (2011) Prevalence and Predictors of Microalbuminuria in Jamaican Children with Sickle Cell Disease. Archives of Disease in Childhood, 96, 1135-1139. https://doi.org/10.1136/archdischild-2011-300628

[15] McBurney, P.G., Hanevold, C.D., Hernandez, C.A., Waller, J.L. and McKie, K.M. (2002) Risk Factors for Microalbuminuria in Children with Sickle Cell Anemia. Journal of Pediatric Hematologyl Oncology, 24, 473-477. https://doi.org/10.1097/00043426-200208000-00013

[16] Alvarez, O., Montane, B., Lopez, G., Wilkinson, J. and Miller, T. (2006) Early Blood Transfusions Protect against Microalbuminuria in Children with Sickle Cell Disease. Pediatric Blood \& Cancer, 47, 71-76. https://doi.org/10.1002/pbc.20645

[17] Becton, L.J., Kalpatthi, R.V., Rackoff, E., Disco, D., Orak, J.K., Jackson, S.M., et al. (2010) Prevalence and Clinical Correlates of Microalbuminuria in Children with 
Sickle Cell Disease. Pediatric Nephrology, 25, 1505-1511.

https://doi.org/10.1007/s00467-010-1536-8

[18] Guasch, A., Navarrete, J., Nass, K. and Zayas, C.F. (2006) Glomerular Involvement in Adults with Sickle Cell Hemoglobinopathies: Prevalence and Clinical Correlates of Progressive Renal Failure. Journal of the American Society of Nephrology, 17, 2228-2235. https://doi.org/10.1681/ASN.2002010084

[19] Schwartz, G.J. and Work, D.F. (2009) Measurement and Estimation of GFR in Children and Adolescents. Clinical Journal of the American Society of Nephrology, 4, 1832-1843. https://doi.org/10.2215/CJN.01640309

[20] Kidney Disease: Improving Global Outcomes (KDIGO) CKD Work Group (2013) KDIGO 2012 Clinical Practice Guideline for the Evaluation and Management of Chronic Kidney Disease. Kidney International Supplements, 3, 1-150.

http://www.kidney-international.org

[21] Viner, R.M. (2012) Life Stage: Adolescence. Annual Report of the Chief Medical Officer 2012, 1-11.

[22] Haymann, J.P., Stankovic, K., Levy, P., Avellino, V., Tharaux, P., Letavernier, E., et al. (2010) Glomerular Hyperfiltration in Adult Sickle Cell Anemia: A Frequent Hemolysis Associated Feature. Clinical Journal of the American Society of Nephrology, 5, 756-761. https://doi.org/10.2215/CJN.08511109

[23] Platt, O.S., Thorington, B.D., Brambilla, D.J., Milner, P.F., Rosse, W.F., Vickinsky, E., et al. (1991) Pain in Sickle Cell Disease-Rate and Risk Factors. The New England Journal of Medicine, 325, 11-16. https://doi.org/10.1056/NEJM199107043250103

[24] Castro, O., Brambilla, D.J., Thorington, B., Reindorf, C.A., Scott, R.B., Gillette, P., et al. (1994) The Acute Chest Syndrome in Sickle Cell Disease: Incidence and Risk Factors. The Cooperative Study of Sickle Cell Disease. Blood, 84, 643-649. http://www.ncbi.nlm.nih.gov/pubmed/7517723

[25] Scheinman, J.I. (2009) Sickle Cell Disease and the Kidney. Nature Clinical Practice Nephrology, 5, 78-88. https://doi.org/10.1038/ncpneph1008

[26] Schwartz, G.J., Munoz, A., Schneider, M.F., Mak, R.H., Kaskel, F., Warady, B.A., et al. (2009) New Equations to Estimate GFR in Children with CKD. Journal of the American Society of Nephrology, 20, 629-637. https://doi.org/10.1681/ASN.2008030287 